\section{LACAN: ENTRE LINGUAGEM E PULSÃO, POR UMA PSICANÁLISE DO SUJEITO}

\author{
Lacan: Between Language and Drive, a Subject's \\ Psychoanalisis
}

\begin{abstract}
Lacan: Entre el Lenguaje y la Pulsión, por un Psicoanálisis Del Sujeto
\end{abstract}

\section{Lacan: Entre la Langue et la Pulsión, la Psychanalyse par un Sujet}

\section{Resumo}

A história de Lacan no campo de saber da psicanálise confunde-se com a construção do conceito de sujeito nesse campo, já que não foi Freud quem estabeleceu suas bases formais. Ao longo do ensino lacaniano, contudo, percebe-se o deslocamento do autor, que parte do centramento na linguagem e passa a caminhar em direção à preponderância do real, o que tem efeitos sobre a noção de sujeito. Aos poucos, fica evidente a dificuldade de Lacan de abranger toda a questão do inconsciente pela linguagem, o que faz com que o autor reconheça inequivocamente o lugar preponderante da pulsão na construção disso que se chama de sujeito de linguagem ou sujeito barrado.

Palavras-chave: sujeito; linguagem; pulsão; simbólico; real.

\section{Abstract}

Lacan's role in psychoanalytic field is very close to the construction of the concept of the subject in this field, since it was not Freud who established their formal foundations. Along the Lacanian school, however, we can see that the author moves from a position centered in language issues toward the preponderance of the real instance, path that has effects on the notion of subject. Gradually, it becomes clear the impossibility of covering the unconscious with the symbolic field, which makes the author clearly recognize the predominant role of drive in the construction of what we call the subject in psychoanalysis.

Keywords: subject; language; drive; symbolic; real.

\section{Resúmen}

La historia de Lacan enel campo delpsicoanálisis es entrelazadaconlaconstruccióndel concepto de sujetoen este campo, ya que no fue Freud quienestableció sus bases formales. A lo largo del ensino lacaniano, podemos, sin embargo, percibireldesplazamientodel autor de lacentralidaddellenguajehacialapreponderancia de lo real, camino que tieneefectos sobre lanoción de sujeto. Poco a poco, se pone de manifiestoladificultad de Lacan de recubrir integralmente lo inconsciente conellenguaje, lo quelohacereconocerel papel predominante de lapulsiónenlaconstrucción de lo que llamamoselsujetoenpsicoanálisis.

Palabras clave: sujeto;lenguage;pulsión; simbólico; real.
Artigo Original

\section{Adriane de Freitas Barroso ${ }^{(1)}$}

1) Pontifícia Universidade Católica de Minas Gerais.
Recebido em: 08/07/2013
Revisado em: $15 / 06 / 2015$
Aceito em: 22/06/2015 


\section{Resumé}

L'histoire de Lacan dansledomaine de lapsychanalyse est liée à laconstructionduconcept de sujetdanscedomaine, caril n'étaitpas Freud qui a établileurs bases formelles. Onpeutpercevoirledéplacement de Lacan de lacentralité de la langue et su marche verslaprépondéranceduréel, cequi a deseffetssurlanotion de sujet. Peu à peu, ildevientclairladifficulté de Lacan de couvrircomplètementl'inconscientaveclalangage, ceq uirendl'auteurreconnaîtlerôle de lapulsióndanslaconstruction de lesujetbarré.

Mots-clés: sujet; langue; pulsión; symbolique; réel.

A história do conceito de sujeito em psicanálise confunde-se com a história do ensino de Jacques Lacan. É ele quem formaliza esse tema central para o edifício teórico psicanalítico - embora haja vestígios do que seria sua préhistória em Freud, o pai da psicanálise contentou-se em utilizar o termo, quase sempre, sem especificidade e como sinônimo de agente de determinada ação.

Situar o sujeito da teoria psicanalítica, portanto, exige que situemos também a incursão lacaniana por ela, estabelecida em um período histórico peculiar: a Segunda Guerra Mundial, que se desenrolou entre 1939 e 1945, alterando drasticamente a configuração política internacional e os modos de vida da época.

$\mathrm{O}$ pós-guerra teve efeitos significativos nos mais variados campos de saber. Na psiquiatria, observou-se um empuxo à medicalização, embalado pelo surgimento de antipsicóticos e antidepressivos. A civilização buscava, por essa via, um antídoto para as marcas deixadas pelo conflito mundial: “(...) o novo ideário que surgia no horizonte impunha-se graças à força que lhe emprestava o impulso tão humano - de nada querer saber disso que determinava a existência" (Cabas, 2009, p. 100).

Diversas abordagens psicanalíticas deixaram-se absorver pelas concepções de cunho biológico que estavam em evidência à época, promovendo uma leitura da obra de Freud como instrumento de adaptação, com foco em estudos sobre disposições e habilidades do cérebro, como linguagem, percepção e raciocínio, calcados em explicações físico-químicas.

Foi buscando deter o que considerava um equívoco da psicanálise pós-freudiana, centrada alhures à questão do inconsciente por conta de uma perspectiva de uniformização do diagnóstico e do tratamento, que Lacan inaugurou sua proposta de retorno a Freud. Retomando a frase freudiana "wo es war, sollichwarden" (Freud, 1933/1996d), que teria sido lida, a seu ver, como uma "espacialização grosseira" (Lacan, 1986, p. 264), como se a conquista analítica dissesse respeito a um alargamento do domínio do eu e não à assunção do inconsciente pelo ato da palavra, Lacan sustenta que o que estaria realmente em jogo na expressão seria, pelo contrário, o crepúsculo do imaginário e a ascensão do sujeito do inconsciente - cujo símbolo, S, faz homofonia com o Es freudiano (isso, em alemão).

$\mathrm{O}$ "retorno a Freud" empreendido por Lacan, portanto, está ligado ao resgate do primado da interpretação, da intenção simbólica da análise, e culminou não apenas em uma retomada de conceitos freudianos já existentes, mas também, paulatinamente, em constatações que exigiram do autor novas construções e leituras, originalmente lacanianas.

O conceito de sujeito é uma das mais significativas delas. O termo, contudo, não era inédito em outros campos de saber, sendo já utilizado há séculos por filósofos e pelo senso comum. Exigiu, por isso, árduo trabalho para clarear sua especificidade na psicanálise, diferenciando-o do eu e de qualquer categoria preexistente, calcada, por exemplo, no conhecimento de si pela via da razão e do pensamento, como sugeria Descartes.

Foi pela via da ligação significante/significado que Lacan cunhou, inicialmente, uma espécie de algoritmo do sujeito, uma regra fundamental aplicável à operação analítica. Ela demonstra a crença em um saber no real, que teria sua existência voltada para significar, a partir de leis do significante que se impõe a ele e o dominam.

Ao longo de seu ensino, contudo, Lacan foi interessando-se cada vez mais em repercutir o que, do real, escapava ao sentido, e foi essa sua maior descoberta. Ainda no Seminário 4 (Lacan, 1995), por exemplo, há a indicação de sua crença na existência de um resto no funcionamento do significante:

(...) tudo o que se apresenta na vontade, a tendência, a libido do sujeito é sempre marcado pelo vestígio de um significante - o que não exclui que talvez haja outra coisa na pulsão ou na vontade, algo que não é de modo algum marcado pela impressão do significante (Lacan, 1995, p. 47).

Freud, por sua vez, não ignorava o fato de que o sujeito não é todo representável pelo simbólico. Em 1919, o autor (Freud, 1919/1996a) já se via às voltas com os casos de neuroses traumáticas resultantes do pós-guerra, que demonstravam, como lembram Castro e Rudge (2012), a existência de outra formatação dos sintomas, refratária à abordagem clínica pela via da interpretação, da decifração. Naquela época, a análise das resistências cedeu espaço à consideração freudiana sobre a pulsão de morte, o que permite considerar que o simbólico nunca se mostrou suficiente para recobrir todo o real na teoria psicanalítica.

Para constatar essa impossibilidade, Lacan atravessou um longo período de ênfase no simbólico para, finalmente, chegar ao primado do real, radicalizando sua importância a ponto de abalar os alicerces da própria noção de sujeito 
do inconsciente, o que exigiu, finalmente, um conceito que lhe viesse em suplemento: o falasser. No presente artigo, propõe-se focar a construção do conceito de sujeito no período pré-falasser, no que são considerados o primeiro e o segundo momentos do ensino lacaniano.

\section{Pré-história do ensino de Lacan: através do espelho, o imaginário}

Os textos iniciais de Lacan são claros na tarefa de situar o eu na instância imaginária. Lacan dá ao eu o status de uma apercepção, no sentido filosófico do termo: "Para a filosofia, o termo apercepção denota uma ação pela qual a mente amplia ou intensifica a consciência de seus próprios estados internos e representações" (Cabas, 2009, p. 119).

Pela lógica de funcionamento do eu, o corpo do infans seria inicialmente recortado por pulsões sem orientação, que imprimiriam nele uma fragmentação primordial, orgânica. Essa insuficiência só seria superada pelo estádio do espelho, diz Lacan (1998a, p. 100). A situação que ilustra tal estádio é conhecida: Uma criança entre seis e dezoito meses de idade experimenta o júbilo diante de seu reflexo, sob o olhar de um cuidador. Esse reconhecimento ocorre antes de qualquer controle motor ou maturação biológica e antecipa, pela imagem, a unidade do corpo. Constrói-se assim uma “(...) linha de ficção para sempre irredutível” (Lacan, 1998a, p. 98), sendo o eu tomado como referência, de maneira alienada e artificial, a partir do que recebe do exterior. A busca por uma imagem como representação sólida de si vela a fluidez e a imaterialidade do inconsciente e faz uma marca indelével na construção do sujeito: "No interior do sujeito, (o eu) não é senão um sintoma privilegiado. É o sintoma humano por excelência, é a doença mental do homem" (Lacan, 1986, p. 25).

Agênese do sujeito, portanto, é uma imagem que vem do exterior e traz um desconhecimento sistemático da realidade que nunca chega a ser eliminado, sendo uma configuração insuperável, afirma Ogilvie (1991). Esse exterior não deve, então, ser entendido meramente como "de fora", porque está em relação intrínseca ao próprio sujeito, fazendo com que constituição e perda sejam avessos dialéticos.

O estádio do espelho de Lacan reformula o conceito freudiano de narcisismo. Correlativamente à construção do eu, funda-se a relação com o outro - tanto o outro como semelhante quanto com o próprio corpo como exterior.

A relação imaginária atravessa a linha inconsciente

\section{O Esquema}

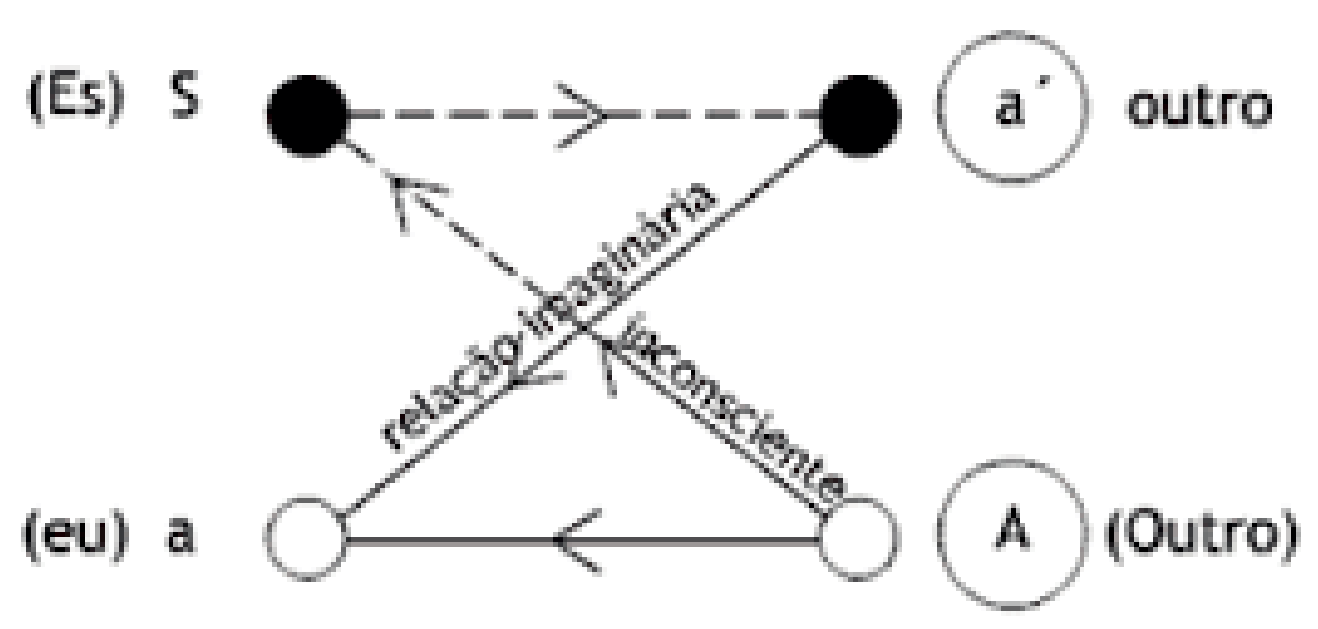

Figura 1. Esquema L (Lacan, 1985, p. 142).

que liga sujeito e Outro, sendo estabilizada por esse atravessamento. Rudge (1998) explica que, em Freud, esse é o papel do narcisismo secundário: Acrescentar ao narcisismo primário o registro do simbólico. Funda-se um novo lugar, fazendo surgir o sujeito dividido, tocado pelo significante.
O Outro não é simplesmente o outro que está ali, mas literalmente o lugar da palavra. Existe, já estruturado na relação falante, este mais-além, este grande Outro para além do outro que vocês apreendem imaginariamente, este Outro suposto que é o sujeito como tal, o sujeito em que a fala de vocês se constitui, porque ele pode não somente acolhê-la, percebê-la, mas também responder a 
ela (Lacan, 1995, p. 80). ${ }^{1}$

O fato de a identificação do eu a esse reflexo só ser validada se subordinada à intervenção da linguagem resume a trajetória que orienta todo o primeiro ensino de Lacan. Trata-se de uma tradução de conceitos do imaginário ao simbólico: "Ao fazer o simbólico interferir no imaginário, Lacan já está separando os dois registros e promovendo uma ascensão do simbólico através da significantização dos elementos até então imaginários" (Machado, 2005, p. 56). Tem-se uma imagem de si que se conjuga a um olhar que vem de fora e triangula a relação eu-outro. Sem esse olhar, ficarse-iam retidos no transitivismo próprio às imaginarizações, diz Machado (2005). É ao Outro, (A), que se visa, embora o eixo imaginário aprisione, em uma medida, na ficção do eu (a-a'), que opera como barreira. Imaginário e simbólico atrelam-se e interpõem-se em Lacan.

Não creio que haja dois tempos no que ensinei algum dia, um tempo que estaria centrado no estádio do espelho e no imaginário e, depois disso, no momento de nossa história que é demarcado pelo "Relatório de Roma", na descoberta que eu teria feito, subitamente, do significante. (...) Não é de hoje que o entre jogo dos dois registros tem sido intimamente trançado por mim (Lacan, 2005, p. 39).

$\mathrm{Na}$ realidade social atual, percebe-se uma subversão nessa relação entre simbólico e imaginário. Laurent e Miller (2005) atentam para o fato de o simbólico mostra-se, hoje, dominado pela instância imaginária ou em continuidade com ela, sem condições de limitá-la. A consequência de um simbólico que perde força como mediação entre eu e objeto é que se escamoteia o fato de que o que se vê no espelho é apenas reflexo, ilusão. Nem tudo é captado pela imagem, havendo sempre um resto não assimilável, não especularizável. Barroso (2006) ressalta que a imagem é sempre dependente do original, sendo mera reprodução invertida do mesmo, e que hoje essa dependência encontrase elidida: $\mathrm{O}$ mercado desveste as imagens de seu contexto para multiplicá-las em um deslocamento infinito. Tal multiplicidade de imagens pacificadoras do eu que oferece o contexto social, continua Barroso (2006), serve para tentar compensar a condição de incompletude do sujeito.

É o interesse de Lacan pelo imaginário que funda seu nome na teoria psicanalítica. Contudo, será sobre a centralidade do simbólico que o ensino lacaniano propriamente dito, como reconhecido por ele, irá se desenvolver, dando a essa instância lugar privilegiado no trabalho de reelaboração de conceitos freudianos. Lacan avança com a obra de Freud em uma abordagem que sai do imaginário e caminha a passos firmes para a instância

1 Ao longo do ensino de Lacan, o conceito de Outro ganha diversas leituras, sobre as quais este trabalho não tem a intenção de discorrer mais longamente simbólica para, finalmente, desaguar no real em seu último momento.

\section{Do imaginário ao simbólico, o primeiro ensino de Lacan}

Tropeço, desfalecimento, rachadura. Numa frase pronunciada, escrita, alguma coisa se estatela. Freud fica siderado por esses fenômenos, e é neles que vai procurar o inconsciente (Lacan, 1998b, p. 30).

É em 1953, com o texto Função e Campo da Palavra e da Linguagem em Psicanálise, que Lacan (2003) reconhece o início de seu ensino público, tomando suas elaborações prévias sobre o imaginário como seus "antecedentes".

O texto celebra a importância da linguagem e da concepção de estrutura - registra-se nele, por exemplo, as célebres noções de inconsciente estruturado como uma linguagem e de simbólico como verdade do imaginário. $\mathrm{O}$ acesso ao mundo é compreendido, naquele momento, como mediado por uma estrutura com lugares definidos, que opera como uma grade de leitura justaposta ao real.

Nesse pano de fundo, Lacan compreende a experiência analítica ${ }^{2}$ como possibilidade de se tomar a palavra e, a partir dela, recontar uma história. A lógica temporal de tal empreitada não é linear, tratando de um passado que, por ser historiado no presente, é renovado a cada relato. Em lugar da rememoração, a reconstrução; em lugar de relembrar, reescrever. É assim que o sujeito poderia vir a surgir, tendo sua existência não precedente à linguagem, mas decorrente dela.

Naquele momento, Lacan (1986) atribuía duas funções distintas à palavra. Enquanto localizada no eixo imaginário, ela teria a tarefa de mediação entre eu e outro; já em sua função de revelação, deslocar-se-ia para o eixo simbólico e faria emergir a linguagem como campo do Outro. Essa concepção dual atrelava-se aos conceitos lacanianos de palavra vazia e palavra plena, respectivamente (Lacan, 2003). A palavra plena seria o objetivo da experiência analítica, que buscaria realizar a verdade do sujeito, abandonando a posição do mestre para revelar um saber sobre o fato de essa verdade nunca ser inteira, porque sempre passível de interpretação e submetida às variações da palavra.

O engano e a dúvida passam, dessa forma, a ser tomados por Lacan como inexoráveis ao sujeito da linguagem.

Nossos atos falhados são atos que são bem-sucedidos,

2 A expressão lacaniana "experiência analítica" une, segundo Miller (2011), as vertentes tanto do tratamento quanto da formação, sendo fruto da oposição de Lacan à separação entre análise leiga e didática promovida pela InternationalPsychoanalyticalAssociation (IPA). 
nossas palavras que tropeçam são palavras que confessam. Eles, elas, revelam uma verdade de detrás. No interior do que se chamam associações livres, imagens do sonho, sintomas, manifesta-se uma palavra que traz a verdade. Se a descoberta de Freud tem um sentido é este - a verdade pega o erro pelo cangote, na equivocação (Lacan, 1986, p. 302).

O sujeito do inconsciente, sustentado pela vertente simbólica, põe em evidência a importância da noção de estrutura no ensino de Lacan. De forma bastante simplificada, compreende-se por estrutura uma maneira específica de se abarcar elementos, colocando em plano secundário sua natureza e suas características para enfatizar as relações guardadas entre eles (Dor, 1989). Os objetos devem pertencer a um mesmo agrupamento para ser possível fazer surgir essas relações - que podem ser de semelhança, oposição, transformação etc. - e sua lei comum. Os significantes são exemplos de elementos articulados segundo leis de uma ordem fechada, razão pela qual se fala em cadeia significante.

Foi o linguista Ferdinand de Saussure que trabalhou a noção de estrutura de forma mais inovadora. Enquanto a concepção linguística clássica definia como função do signo representar um objeto, entendendo a linguagem como instrumento de nomeação, Saussure (2006) foi quem, em vez de abordar os objetos como ponto de partida e deduzir relações a partir deles, considerou que são justamente as relações que os determinam. O signo deixava de ser visto como o que une uma coisa a um nome e passava, aí, a unir um conceito (significado) a uma imagem acústica (significante) - o segundo em posição dominante em relação ao primeiro.

Lacan utiliza a elaboração saussuriana em seu ensino,

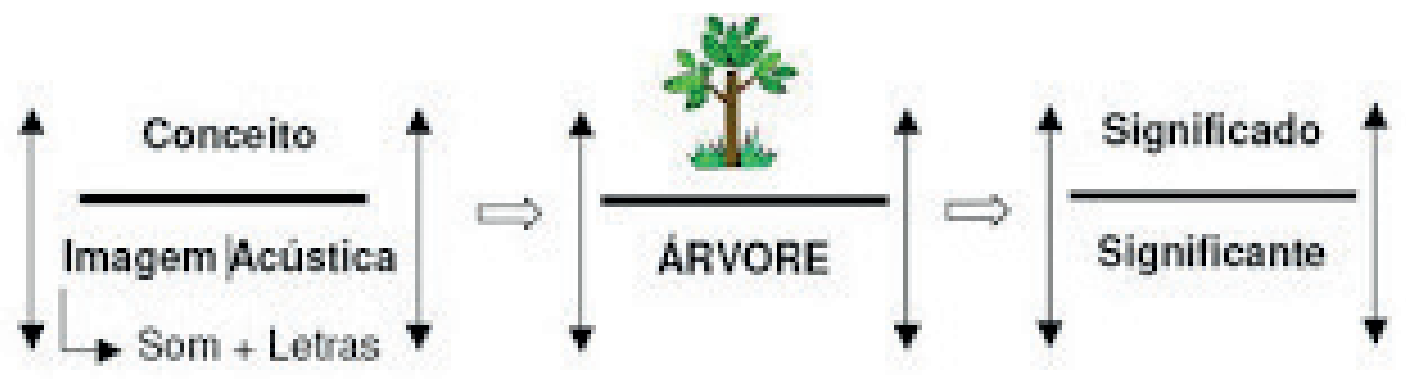

Figura 2. O signo em Saussure (Saussure, 2006, p. 81).

apropriando-se dela e extraindo da linguística conceitos originalmente psicanalíticos. A leitura lacaniana destitui o significante de sua função representativa, dissociando-o do significado e dando-lhe autonomia. O significante, diz Lacan, não significa nada por si só, sendo usado pelo sujeito "(...) precisamente para enganar sobre o que se tem de significar” (Lacan, 2002, p. 213). A fala vela e desvela, carregando toda ordem de significações e evidenciando a primazia do significante sobre o significado. Lacan inverte o algoritmo saussuriano (figura 3).

A desamarração entre significante e significado enfatiza a relação entre esses elementos, representada pela barra que os separa no algoritmo acima. Ela indica a resistência, a impossibilidade da associação biunívoca entre os dois termos (Antunes, 2002). Indica também a substituição do termo de baixo pelo de cima, ou o suporte do segundo pelo primeiro. É esse deslizamento o que Lacan entende como metonímia, demonstrando ser possível encontrar tal autonomia do significante no inconsciente já no texto freudiano e em sua noção de interpretação.

Se o significante não se atrela a um significado

\section{Significante}

\section{Significado}

Figura 3. O algoritmo significante/significado em Lacan (Lacan, 2002)

único, seu valor só pode se dar em termos relativos. Ele não é isolável, estando sempre em relação binária $-\mathrm{S}_{1}$ $\mathrm{S}_{2}$-, definindo-se por sua diferença quanto ao seguinte e guardando com os demais elementos uma articulação repetitiva, de deslocamento e substituição (Lacan, 2008). Nesse movimento de constante reenvio, o desejo é o que aparece como resíduo. 
O desejo se situa na dependência da demanda - a qual, por se articular em significantes, deixa um resto metonímico que corre debaixo dela, elemento que não é indeterminado, que é uma condição ao mesmo tempo absoluta e impegável, elemento necessariamente em impasse, insatisfeito, impossível, desconhecido, elemento que se chama desejo (Lacan, 1998b, p. 146).

O sujeito de desejo é, conclui-se, função da metonímia significante: "Desidero, é o cogito freudiano" (Lacan, 1998b, p. 147). Determinado pelo que vem do Outro, exterior a si próprio, é como objeto que ele é representado, sendo falado antes de ser falante. A linguagem funciona previamente ao nascimento do ser humano, impedindo qualquer concepção de um Isso instintual ou natural (Lacan, 1995).

Porque um significante não pode significar a si mesmo, o significado vem sempre da relação "entre dois". O ensino de Lacan enfatiza, nesse circuito, que sujeito é o que surge na trajetória de um significante a outro, na própria metonímia do desejo, mais no movimento em si do que em um elemento específico. Ele surge para, logo depois, se apagar prontamente (Lacan, 2008) - quando chega a $\mathrm{S}_{2}$, já não está lá, nunca alcançando, de fato, seu destino. Existe aí um movimento de eterno recomeço.

Nomeia-se sujeito barrado (\$) isso que é segundo em relação ao significante, ao campo do Outro como campo da linguagem, ganhando consistência apenas parcial por ser pura articulação. Ele não pode ser representado, a não ser que haja uma perda, um resto.

Buscando situar o sujeito na divisa entre linguagem e pulsão, entre o representável e o que escapa à representação, Lacan caminha a passos largos em direção ao segundo momento de seu ensino.

\section{Lacan além de Freud: especificidades do segundo ensino}

O Seminário 11 (1964), intitulado Os Quatro Conceitos Fundamentais da Psicanálise (Lacan, 1998b), define um ponto de virada no ensino lacaniano: O momento em que a oposição de Lacan às práticas da International Psychoanalytical Association (IPA) resulta em sua ruptura com a instituição e na fundação da École Freudienne de Paris.

O seminário marca, portanto, um reinício. Ao levantar uma crítica sobre a manutenção imutável da teoria psicanalítica freudiana, Lacan toca na importância do avanço teórico e clínico, e é por se autorizar nesse avanço que retoma a noção de inconsciente em Freud para construir seu conceito de sujeito: "É justo que pareça novo que eu me tenha referido ao sujeito, quando é do inconsciente que se trata" (Lacan, 1998b, p. 46).

A partir de 1964, Lacan imprime ao inconsciente um caráter mais marcado pela descontinuidade e pela pulsação, atrelando-o ao funcionamento da pulsão e não apenas à linguagem e explicitando, com isso, a parceria ineliminável do significante com o real (Darriba, 2005). Real, simbólico e imaginário surgem imbricados, o que justifica a construção de novos conceitos lacanianos de fronteira, como falo, fantasia, objeto, sintoma. Foi preciso consentir em articular o que é da ordem significante com o que é real para sustentar a concepção de sujeito.

É nos hiatos, nos equívocos, por entre os significantes que o sujeito do inconsciente passa a ser encontrado, o que determina seu caráter de dessubstancialização: “Que o sujeito como tal está na incerteza em razão de ser dividido pelo efeito da linguagem, é o que lhes ensino, eu enquanto Lacan, seguindo os traços da escavação freudiana" (Lacan, 1998b, p. 178). Nenhum significante, por si só, é suficiente para dar-lhe consistência.

A lógica sexual do inconsciente aparece cada vez mais relacionada ao real, permitindo que a estrutura inclua o que vai além da significação. O Complexo de Édipo, por exemplo, passa a contemplar gozo e sentido: Diante do gozo materno, surge o significante paterno como resposta, fazendo com que a cadeia significante pare de deslizar na busca do que poderia the atribuir significado. O falo passa a ter caráter de conector entre gozo e linguagem, assim como a pulsão fazia fronteira entre somático e psíquico em Freud. Ele pode ser lido por suas duas faces: é [ $\varphi]$, o objeto imaginário que condensa o gozo dessa instância e transfere-o para o simbólico, e é $[\Phi]$, significante do gozo, representando a parcela da libido que permanece no eu e fica alheia ao investimento pulsional no objeto.

A falta tem estatuto simbólico: Exige considerar que algo deveria estar ali em que ela se apresenta. Para constatála, é necessário que se diga "a conta está errada" (Lacan, 2008), que haja, portanto, uma contagem e um elemento significante ausente. Logo, o falo toca a questão da lacuna na cadeia, que é o que veicula o desejo.

No esquema óptico adaptado por Lacan (2005) (Figura 4), vê-se que, da montagem original do esquema óptico, à esquerda, uma parte não é representável, não pode ser imaginarizada do lado do Outro, sendo ela a parcela de libido que continua investida no eu. O falo é justamente essa falta simbólica do objeto imaginário que fica ausente, $(-\varphi)$, escamoteado na imagem virtual, deixando uma lacuna (Triska, 2011) e escapando à representação.

Em lugar disso que deveria vir a menos, contudo, pode surgir algo destacado da imagem, aspecto que Lacan aborda com a construção do conceito de o objeto $a$. A angústia é o afeto diante do surgimento desse objeto que deveria se manter oculto, fora da visão do sujeito: "Não se trata da perda do objeto, mas da presença disto: de que os objetos não faltam" (Lacan, 2005, p. 64). É o real irredutível, o gozo que resta e não é subtraído do ser vivo pela representação. Associa-se à parte perdida pelo sujeito por sua entrada na 

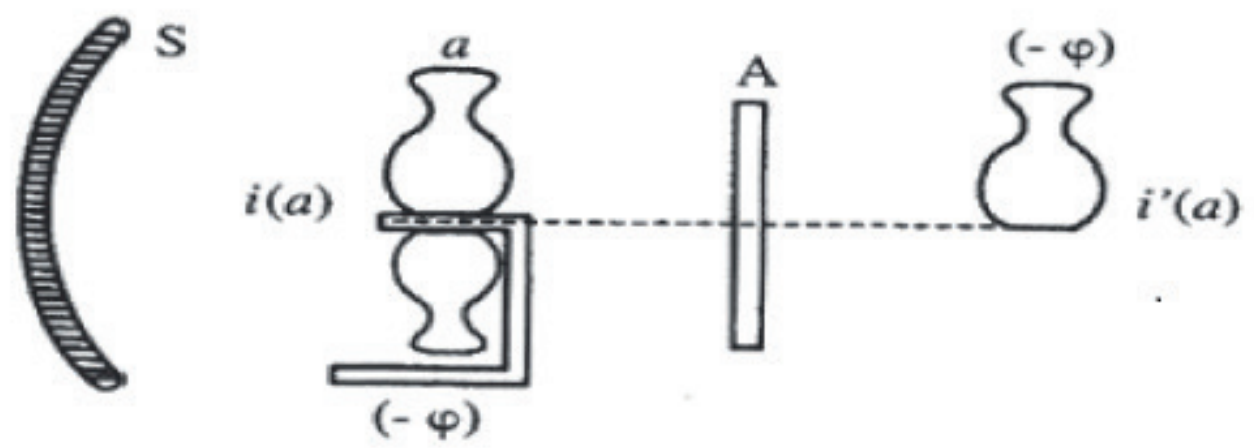

Figura 4. Esquema óptico de Lacan a partir do Seminário 10 (Lacan, 2005, p. 54).

linguagem, no que Lacan (1998b) assemelha à placenta, embora continue a ter incidência no ser falante.

Assim como o falo, o objeto $a$ faz limite ao representável, não pertencendo exclusivamente nem à imagem nem à representação significante (Novaes, 2007), o que permite abordar a libido em suas duas condições: significante $(\varphi)$ e não-significante $(a)$. Constata-se que ( $-\varphi)$ e $a$ equivalem-se como avessos, sendo o objeto $a$ a presença do que deveria vir negativizado: “(...) no coração do objeto $a$ existe o menos phi da castração, cujo objeto é, de certo modo, apenas um envelope" (Miller, 2005, p. 260). Conjugam-se esses dois elementos como um furo e seu tampão em uma relação de metáfora.

Se o falo foi, em um momento específico, o representante do triunfo do simbólico na obra lacaniana, o objeto $a$ é o que vem testemunhar a exigência de construção de um mais além para abordar a pulsão, na medida em se constata que algo resiste à função da linguagem. No perpétuo deslizamento do significado sob o significante, há o sentido jamais atingido. Em vez da barra, da metáfora, o ensino de Lacan passa a enfatizar o corte, a queda: A primeira faz alusão à supressão, apagamento, morte, enquanto o segundo fala mais de uma separação, embora deixe um resto.

O sujeito de desejo é aquele que questiona os efeitos do significante, sendo barrado de um gozo que surge como negativizado, como falta-a-ser. Em sua outra face, está o sujeito de gozo, alienado em sua relação com o objeto $a$, com esse a mais de satisfação. Diante da divisão promovida pela linguagem, o sujeito apela para o objeto como aquilo que o complementaria, que o designaria, tornando-se, nesse trajeto, equivalente a ele. A verdade sobre sua identificação ao objeto, todavia, só aparece em fendas que se abrem repentinamente, contingencialmente. Quando essa abertura acontece, o desnudamento do que deveria ficar oculto entre a cena e o mundo (Novaes, 2007), o que advém é a angústia.

Vieira (2009) explica que o sujeito da psicanálise não é alguma coisa, o que o distingue da subjetividade, que é sempre um conjunto de atributos palpáveis. Sujeito é sempre presença de uma ausência, daquilo que fica de fora do quadro, do que resiste e repete. É centrando-se nesse "de fora" que surge o conceito freudiano de pulsão de morte e que Lacan, mais tarde, pode trabalhar pela via do gozo condensado no objeto $a$. O ser do sujeito ganha, como contraponto, esse objeto com o qual ele faz parceria.

Não se pode pensar o sujeito sem este seu contraponto. O primeiro é vazio, faz corte e acontecimento, o segundo é sólido, opaco no qual se tropeça. Um é fugidio e o outro presença imperativa. Um é "?" e o outro "!". (Vieira, 2009, p. 336)

É justamente sobre isso que não se interpreta, que não se esgota pela via da linguagem, que o Seminário 11 (Lacan, 1998b) de Lacan avança, segundo Soler (1997), atrelando a pulsão tanto ao desejo quanto ao gozo. Ao definir os quatros conceitos fundamentais da psicanálise, Lacan abre mão de listar entre eles o desejo para dar lugar à pulsão, que estava esmorecida em seu ensino até então e mostrou-se fundamental para que suas elaborações prosseguissem.

Por ser consequência da desprogramação promovida pela linguagem no ser humano, a pulsão instaura a demanda, que não se satisfaz plenamente com objeto algum, sempre distinta do que pede, portando um significado inacessível, incapturável. Freud (1919/1996b) já havia encontrado na pulsão algo que insiste silenciosamente, extraindo dessa insistência uma satisfação que o sujeito não reconhece. Nesse movimento de repetição desligada do significante, Lacan também vai localizar o caráter acéfalo da pulsão, conferindo a ela suas duas faces, autômaton e tiquê repetição da cadeia significante e compulsão à repetição desligada da cadeia, respectivamente.

Colocando-se em evidência a relação entre significante e pulsão na construção do sujeito, este passa a estar localizado muito mais próximo do tropeço do que de um resultado a 
que se chegaria por algo como um uso bem-sucedido da linguagem. O simbólico é apenas sua borda, uma vez que a fala não o realiza, sendo, ao contrário, testemunha de sua falta-a-ser, "máquina de se perder" (Miller, 2005, p. 12). Há sempre um resto como condição inerente à cadeia significante. Logo, o simbólico está também submetido ao gozo.

A ordem simbólica ao mesmo tempo não-sendo e insistindo para ser, eis a que visa Freud quando nos fala do instinto de morte como sendo o que há de mais fundamental - uma ordem simbólica em pleno parto, vindo, insistindo para ser realizada ${ }^{3}$. (Lacan, 1985, p. 407)

É na condição de consentir com a identificação a um significante que o sujeito pode ser fundado, mas é também por essa via que se vê elidido, no que Lacan (1998b) chama de afânise ou fading. Se a escolha pela condição de sujeito acontece, é preciso uma anuência para se deixar dividir pela linguagem. Um traço inicial deve ser entalhado no inconsciente, tornando-se o 1 do qual o sujeito parte (Lacan, 2005), significante no real, marca distintiva a que se ficará, a partir daí, assujeitado, sem que o próprio sujeito o saiba.

$\mathrm{O}$ traço unário é esse entalhe totalmente despersonalizado, próximo ao que Machado (2005) define como notação mínima, o que o remete ao Einzigerzug, recalque originário de que fala Freud (1996c). Lacan vai aproximá-lo do ideal do eu, significação produzida no campo do Outro que dá, como consequência, a significação do próprio sujeito. Essa marca assegura a existência da repetição no aparelho psíquico, uma vez que, a partir daí, toda a atividade pulsional em direção aos objetos vai ser uma tentativa de reencontrar essa experiência original de satisfação diante da resposta do Outro.

Esse $\mathrm{S}_{1}$ encontra-se desarticulado, fora da série e, por isso, sem efeito de verdade e sem função de representar nada, nem mesmo o sujeito para outro significante. É o Um sozinho, não o par $\mathrm{S}_{1}-\mathrm{S}_{2}$, tendo a função de posicionar o sujeito em um conjunto fechado em relação ao enxame de significantes e inscrever a possibilidade de que, em um segundo momento, o Outro reconheça a unidade de sua imagem, i(a), marcando sua diferença fundamental em relação aos outros elementos. O Outro tem lugar de onipotência justamente pelas insígnias que oferece nesse primeiro dito, constituindo-se como a sustentação da satisfação narcísica.

Portanto, o choro só ganhará estatuto de apelo (S1) quando houver a resposta do agente materno (S2) que confira uma satisfação, de modo a marcar uma pulsação na descontinuidade que diz o que o choro pode significar

3 O termo "instinto", nesse trecho, parece vir como tradução equivocada do que seria a pulsão, equívoco encontrado em muitas edições na língua portuguesa das obras de Freud e Lacan. (do apelo a uma demanda). É, então, por meio do ato que intervém, que haverá a promoção da satisfação e o franqueamento de uma posição (Neves; Vorcaro, 2011, p. 282).

Embora a identificação ao traço unário seja a operação inaugural da relação entre sujeito e Outro, de onde o sujeito extrai seu ser, mantém-se também uma identificação do sujeito a um vazio que esse significante não recobre. $\mathrm{O}$ sujeito não se inclui inteiramente em $\mathrm{S}_{1}$, remetendo-se, como consequência, a um ponto radical e arcaico, aquém de qualquer identificação. Algo da representação fica de fora do que se pode oferecer como resposta, da possibilidade de significação com as palavras transmitidas pelo Outro, já que a ele também falta o significante derradeiro - não todo sujeito pode surgir por essa via, persistindo um resto oculto, que o localiza em um fora de sentido, no deslizar da cadeia significante.

Escolhemos o ser, o sujeito desaparece, ele nos escapa, cai no não-senso - escolhemos o sentido, e o sentido só subsiste decepado dessa parte de não-senso que é, falando propriamente, o que constitui na realização do sujeito, o inconsciente (Lacan, 1998b, p. 200).

É necessária, em um segundo tempo, uma escolha, a participação ativa do sujeito para buscar saber o que ele é para além desse significante que o Outro lhe oferece: "Separare, separar, conclui-se aqui em se parere, gerar a si mesmo" (Lacan, 1998c, p. 857). Será essa a busca da experiência analítica.

Com o sujeito, portanto, não se fala. Isso fala dele, e é aí que ele se apreende, e tão mais forçosamente quanto, antes de - pelo simples fato de isso se dirigir a ele - desaparecer como sujeito sob o significante em que se transforma, ele não é absolutamente nada. Mas esse nada se sustenta por seu advento, produzido agora pelo apelo, feito no Outro, ao segundo significante. (Lacan, 1998c, p. 849)

\section{Conclusão: falasser, o que, do sujeito, desemboca no real}

O primeiro e o segundo ensinos de Lacan são frequentemente tratados, juntos, como "a primeira clínica lacaniana". A radicalidade do autor em direção ao real no terceiro e último tempo de seu texto faz tanto efeito que determina, então, o que se considera uma segunda clínica, uma maneira inédita de conceber a clínica psicanalítica de orientação lacaniana. Pela via do que é rebelde ao inconsciente em sua modalidade simbólica, Lacan retira a centralidade do conceito de sujeito e debruça-se na 
construção de outro conceito que lhe vem em suplemento, o falasser.

Essa construção é entendida como o momento em que Lacan constata a centralidade do real e limita a solução universal do Complexo de Édipo. A fala não é o que funda o ser, tarefa que passa a ser do gozo. Ao contrário, ela é o que habita de maneira secundária e oportunista o real do falasser: "A questão é antes saber por que um homem dito normal não percebe que a fala é um parasita, que a fala é uma excrecência, que a fala é uma forma de câncer pela qual o humano é afligido" (Lacan, 2007, p. 92).

O sujeito puro da fala cede lugar a um corpo falante, que extrai do gozo a razão última de seus ditos. O último ensino de Lacan é a admissão de que o sujeito não vem apenas como produto dos significantes de sua história, exigindo, em suplemento, o falasser. O real limita a função do ser do sujeito, que se liga a uma construção fictícia, pela via do sentido. O ser não passa de um equívoco, de uma tela que se sobrepõe ao real, ao fato de haver um corpo em que o gozo incide. A partir desse momento do texto lacaniano, o que há por definição é o gozo.

Que lugar resta ao sujeito na clínica do falasser? Indo ainda mais além, que lugar resta à própria concepção de clínica como fundada pelo simbólico, no momento em que toda construção significante parece relegada a segundo plano? Como se sustenta a noção de um inconsciente estruturado como uma linguagem? Essas são perguntas que se deixa como um convite.

\section{Referências}

Antunes, M. C. C. (2002). O discurso do analista e o campo da pulsão: Da falta de gozo ao gozo com a falta. Tese de Doutorado, Universidade Federal do Rio de Janeiro, Rio de Janeiro, RJ.

Barroso, S. F. (2006). O uso da imagem pela mídia e sua repercussão na subjetividade contemporânea. Psicologia em revista, Belo Horizonte, 12(9), 92-97.

Cabas, A. G. (2009). O sujeito na psicanálise de Freud a Lacan: Da questão do sujeito ao sujeito em questão. Rio de Janeiro: Jorge Zahar.

Castro, S. L. S., \& Rudge, A. M. (2012). Notas sobre a clínica do trauma. Fractal: Revista de Psicologia, Rio de Janeiro, 24(1), 81-94. Recuperado de http://www.scielo. br/scielo.php?pid=S1984-02922012000100006\& script=sci_arttext $>$ em 20 de outubro de 2013.

Darriba, V. (2005). A falta conceituada por Lacan: da coisa ao objeto a. Ágora, Rio de Janeiro, 8(1). Recuperado de $\quad<$ http://www.scielo.br/scielo.php?script=sci_
arttext\&pid=S1516-14982005000100005\&lng=en\&nr $\mathrm{m}=$ iso $>$ em 14 março de 2012.

Dor, J. (1989). Introdução à leitura de Lacan. Porto Alegre: Artes Médicas.

Freud, S. (1996a). Introdução a “A psicanálise e as neuroses de guerra”. In J. Strachey (Ed.), Edição standard brasileira das obras psicológicas completas de Sigmund Freud (Vol. 17, pp. 221-234). Rio de Janeiro: Imago. (Originalmente publicado em 1919)

Freud, S. (1996b). O estranho. In J. Strachey (Ed.), Edição standard brasileira das obras psicológicas completas de Sigmund Freud (Vol. 17, pp. 235-276). Rio de Janeiro: Imago. (Originalmente publicado em 1919)

Freud, S. (1996c). A psicologia de grupo e a análise do ego. In J. Strachey (Ed.), Edição standard brasileira das obras psicológicas completas de Sigmund Freud (Vol. 18, pp. 79-156). Rio de Janeiro: Imago. (Originalmente publicado em 1921)

Freud, S. (1996d). Novas conferências introdutórias sobre psicanálise - conferência XXI: A dissecção da personalidade psíquica. In J. Strachey (Ed.), Edição standard brasileira das obras psicológicas completas de Sigmund Freud (Vol. 18, pp. 13-78). Rio de Janeiro: Imago. (Originalmente publicado em 1933)

Lacan, J. (1985). O seminário, livro 2: O Eu na teoria de Freud e na técnica da psicanálise(1954-1955). Rio de Janeiro: Jorge Zahar.

Lacan, J. (1986). O seminário, livro 1: Os escritos técnicos de Freud (1954). Rio de Janeiro: Jorge Zahar.

Lacan, J. (1995). O seminário, livro 4: A relação de objeto (1956-1957). Rio de Janeiro: Jorge Zahar.

Lacan, J. (1998a). O estádio do espelho como formador da função do eu. In J. Lacan, Escritos. Rio de Janeiro: Jorge Zahar.

Lacan, J. (1998b). O seminário, livro 11: Os quatro conceitos fundamentais em psicanálise (1964). Rio de Janeiro: Jorge Zahar.

Lacan, J. (1998c). Posição do inconsciente no Congresso de Bonneval. In J. Lacan, Escritos. Rio de Janeiro: Jorge Zahar.

Lacan, J. (2002). O seminário, livro 3: As psicoses (19551956). Rio de Janeiro: Jorge Zahar. 
Lacan, J. (2003). Discurso de Roma. In J. Lacan, Outros escritos. Rio de Janeiro: Jorge Zahar.

Lacan, J. (2005). O seminário, livro 10: A angústia (19621963). Rio de Janeiro: Jorge Zahar.

Lacan, J. (2007). O seminário, livro 23: Osinthoma (19751976). Rio de Janeiro: Jorge Zahar.

Lacan, J. (2008). O seminário, livro 16: De um Outro a outro (1968-1969). Rio de Janeiro: Jorge Zahar.

Laurent, E., \& Miller, J.-A. (2005). El Otro que no existe y sus comités de ética. Buenos Aires: Paidós.

Machado, O. M. R. (2005). A clínica do sinthoma e o sujeito contemporâneo. Tese de Doutorado,Universidade Federal do Rio de Janeiro, Rio de Janeiro, RJ.

Miller, J.-A. (2005). Silet: Os paradoxos da pulsão, de Freud a Lacan. Rio de Janeiro:Jorge Zahar.

Miller, J.-A. (2011).A obra de Lacan. Seminário de Orientação Lacaniana III, 13, Paris, 2011. Escola Brasileira de Psicanálise, Belo Horizonte, 2011. Circulação interna.

Neves, B. R., \&Vorcaro, A. M. (2011). Breve discussão sobre o traço unário e o objeto a na constituição subjetiva. Psicologia em Revista, Belo Horizonte, 17(2), 278-290.

Novaes, M. A. (2007). Paradoxos e pertinências clínicas do conceito de identificação no ensino de Jacques Lacan. Tese de Doutorado, Pontifícia Universidade Católica do Rio de Janeiro: Rio de Janeiro, RJ.

Ogilvie, B. (1991). Lacan: A formação do conceito de sujeito. Rio de Janeiro: Jorge Zahar.

Rudge, A. M. (1998). Pulsão e linguagem: Esboço de uma concepção psicanalítica do ato. Rio de Janeiro: Jorge Zahar.

Saussure, F. (2006). Curso de linguística geral. São Paulo:Cultrix.

Soler, C. (1997). O sujeito e o Outro I. InR. Feldstein, B. Fink, \&M. Jaanus, Para ler o Seminário 11 de Lacan: Os quatro conceitos fundamentais da psicanálise (pp. 52-57). Rio de Janeiro: Jorge Zahar.

Triska, V. H. (2011, 31 de maio). Sobre o modelo óptico de Lacan no Seminário 10. Ensaios psicanalíticos[Victor
Hugo Triska blog]. Recuperado de 2011 de: $<$ http://vhtriskaensaios.blogspot.com/search/label/ psican $\%$ C3\%A1lise > em 26 de dezembro.

Vieira, M. A. (2009). Signo e significante. Scilicet: Sinthoma e semblantes(pp. 336-340) (Textos Preparatórios para o VII Congresso Mundial de Psicanálise, Paris, 2010). São Paulo: Escola Brasileira de Psicanálise.

\section{Endereço para correspondência:}

Adriane de Freitas Barroso

Endereço: R. Juiz de Fora, no 115/1206, Barro Preto. Belo Horizonte/MG.

Email: adrianebr@gmail.com 